REVISTA DE DERECHO UNED, núm. 6, 2010

\title{
LAS SOCIEDADES PROFESIONALES DE AUDITORÍA EN LA DOCTRINA DE LA DGRN
}

\author{
ISRAEL HERNANDO AguAYo \\ Abogado
}

Resumen: A través de la doctrina emitida por la Dirección General de los Registros y del Notario, se fijan algunos aspectos conflictivos en cuanto a la regulación de las Sociedades de Auditoría en el marco establecido por la Ley de Sociedades Profesionales.

Para ello se abordarán problemas, tales como, el determinar si una sociedad que tiene por objeto el ejercicio de la actividad profesional de auditoría, debe someterse imperativamente al régimen impuesto por la Ley de Sociedades Profesionales; cuáles son los requisitos que deben cumplirse en la constitución o adaptación de una sociedad profesional de auditoria o de cualquier otra clase, en cuanto a la expresión del objeto social en sus estatutos; determinar si la obligación de adaptación e inscripción de las sociedades profesionales en el Registro Mercantil, es aplicable a la sociedad profesional de auditoria y si en el caso de incumplimiento de dicha obligación de adaptación e inscripción, se le aplicarían las sanciones del cierre registral y la disolución de pleno derecho de la sociedad.

Por último, se hará referencia a los supuestos de sociedades profesionales multidisciplinares, especialmente las de abogados y auditores que son las que mayor polémica suscitan en la actualidad, a la vista del Proyecto de Ley que modificará, entre otros, el artículo 8 de la Ley 19/1988 de 12 de julio, de Auditoría de Cuentas, relativo al principio de independencia.

Palabras clave: sociedad profesional, sociedad mercantil, sociedad de auditoría, auditoría, abogacía, auditor, abogado, Registro Mercantil, objeto social, resolución, DGRN, Disposición Transitoria, ins- 
cripción, adaptación, sanción, cierre registral, disolución, sociedad multidisciplinar.

Abstract: Through the doctrine issued by DGRN, fixing some controversial aspects regarding the regulation of the audit companies within the framework established by the Law of Professional Societies

To do this, we will study issues such as to determine if the Law of Professional Societies must to apply mandatorily to the audit firms; what are the requirements to be completed in the creation or adaptation of a audit professional company or other, with regard to the expression of corporate purpose in their statutes; to determine whether the obligation to adapt and registration of professional company in the Register of Companies is aplicaple to audit professional society and if in the event of a breach of that obligation adjustment and registration, sanctions would be applicable: closing registration and automatic dissolution of company.

Finally, we will refer to the case of multidisciplinary professional companies, especially those of lawyers and auditors who are the most controversy raise today, in view of the Bill will change, inter alia, article 8 of Law 19/1988 of 12 July, Audit of Accounts, respect the rule of independence.

Key words: professional company, trading company, audit company, audit, law, auditor, lawyer, Register of Companies, corporate purpose, decision, DGRN, transitory provision, registration, adjustment, sanction, closing registration, dissolution, multidisciplinary professional companies.

Sumario: I. Introducción.-II. Ámbito de aplicación de la Ley de Sociedades Profesionales: las Sociedades Profesionales de Auditoría.-III. Expresión del objeto social en los estatutos de una Sociedades Profesionales de Auditoría.-IV. Aplicación de la Disposición Transitoria Primera de la Ley de Sociedades Profesionales a las Sociedades Profesionales de Auditoría.-V. Las Sociedades Profesionales de Auditoría Multidisciplinares.-VI. Conclusiones.

\section{INTRODUCCION}

Con fecha 16 de marzo de 2007 se publicó en el Boletín Oficial del Estado número 65, la Ley 2/2007 de Sociedades Profesionales, con el fin de dar cobertura jurídica a las organizaciones profesionales que operan en el ámbito de los servicios profesionales. 
Se trataba de una Ley esperada, ya que ha tenido una gran relevancia en cuanto a los aspectos jurídicos de la organización y desarrollo de determinadas profesiones de gran incidencia actual en nuestra sociedad, como las de los abogados, auditores o médicos, así como en las relaciones entre éstos y sus clientes.

En una sociedad compleja y con un mercado comercial muy agresivo como actualmente se da en la nuestra, la actividad del profesional se ha ido encaminando hacia su formación y especialización en una materia concreta dentro de los conocimientos correspondientes a su profesión, lo que está conllevando a que la actividad aislada del profesional se vea sustituida, cada día con mayor profusión, por la prestación de servicios en forma colectiva.

Así, la Ley 2/2007 en su Exposición de Motivos, justifica la nueva regulación en el hecho de que las organizaciones colectivas que operan en el ámbito de los servicios profesionales han ido adquiriendo una creciente difusión, escala y complejidad, con acusada tendencia en tiempos recientes a organizar el ejercicio de las profesiones colegiadas por medio de sociedades.

En este contexto, la Ley de Sociedades Profesionales tiene por objeto posibilitar la aparición de una nueva clase de profesional colegiado, que es la propia sociedad profesional, mediante su constitución con arreglo a lo establecido en la Ley y su posterior inscripción en el Registro de Sociedades Profesionales del Colegio Profesional correspondiente.

En definitiva, con esta Ley, el legislador pretende facilitar un marco jurídico en el que se puedan desarrollar con plenas garantías las sociedades profesionales hasta ahora inexistentes en nuestro ordenamiento, así como la determinación de los sujetos responsables para con los clientes que hayan contratado, con este tipo de sociedades, la prestación de sus servicios.

Recientemente, la Ley de Sociedades Profesionales ha sido modificada por la Ley 25/2009, de 22 de diciembre, conocida como Ley Omnibus, de modificación de diversas leyes para su adaptación a la Ley 17/2009, de 23 de noviembre, sobre el libre acceso a las actividades de servicios y su ejercicio, la cual incorporó, parcialmente, al derecho español, la Directiva 2006/123/CE del Parlamento Europeo y del Consejo, de 12 de diciembre de 2006, relativa a los servicios en el mercado interior.

Una de las instituciones revisadas por la Ley Omnibus, ha sido la sociedad profesional, ya que el objetivo fundamental de ambas leyes 
es impulsar la eficiencia económica del sector servicios, consolidar en dicho sector las libertades básicas de establecimiento y libre prestación de servicios y suprimir y reducir barreras no justificadas.

Esto no significa que en los servicios profesionales no sea necesaria una regulación específica en atención a los bienes públicos que producen, sino que esa regulación debe ser compatible con el principio general de libre acceso y ejercicio, lo que significa que las eventuales restricciones tienen que respetar tres principios básico: el de reserva de ley, en su sentido formal o de congelación del rango, pues toda restricción sólo puede venir establecida por una norma con rango de ley; el de necesidad, lo que significa que toda restricción sólo puede estar justificada por razones de interés general; y el de proporcionalidad, de modo que la restricción tiene que ser adecuada y no ir más allá de lo estrictamente necesario para obtener la finalidad perseguida.

Teniendo presentes los anteriores principios, las modificaciones realizadas en la Ley de Sociedades Profesionales por la Ley Omnibus, afectan a cinco preceptos:

1. Sociedades multidisciplinares. Las sociedades profesionales podrán ejercer varias actividades profesionales, siempre que su desempeño no se haya declarado incompatible por norma de rango legal.

Sobre las sociedades multidisciplinares, en particular aquellas que tuvieren por objeto el ejercicio de las profesiones de abogacía y auditoria, insistiremos más tarde.

2. Capital y voto. Como mínimo, la mayoría del capital y de los derechos de voto, o la mayoría del patrimonio social y del número de socios en las sociedades no capitalistas, habrán de pertenecer a socios profesionales. (Anteriormente eran exigibles las tres cuartas partes del capital y de los derechos de voto, o las tres cuartas partes del patrimonio social y del número de socios en las sociedades no capitalistas).

3. Órganos de administración. Igualmente habrán de ser socios profesionales como mínimo la mitad más uno de los miembros de los órganos de administración, en su caso, de las sociedades profesionales (antes tres cuartos).

Si el órgano de administración fuere unipersonal, o si existieran consejeros delegados, dichas funciones habrán de ser desempeñadas necesariamente por un socio profesional.

En todo caso, las decisiones de los órganos de administración colegiados requerirán el voto favorable de la mayoría de socios profesionales, con independencia del número de miembros concurrentes. 
4. Regularización. Los requisitos que han de tener los socios deberán cumplirse a lo largo de toda la vida de la sociedad profesional, constituyendo causa de disolución obligatoria su incumplimiento sobrevenido, a no ser que la situación se regularice en el plazo máximo de seis meses (antes tres) contados desde el momento en que se produjo el incumplimiento.

5. Sociedades profesionales de países comunitarios. Serán reconocidas en España como sociedades profesionales las constituidas como tales de conformidad con la legislación de un Estado miembro de la Unión Europea y cuya sede social, administración central y centro de actividad principal se encuentre en el territorio de un Estado miembro, siempre que hayan cumplido los requisitos previstos, en su caso, en dicho país comunitario para actuar como sociedades profesionales.

Por último señalar que las modificaciones introducidas en la Ley de Sociedades Profesionales por la Ley Omnibus, entraron en vigor el 27 de diciembre del 2009.

\section{AMBITO DE APLICACIÓN DE LA LEY DE SOCIEDADES PROFESIONALES: LAS SOCIEDADES PROFESIONALES DE AUDITORIA.}

En estas líneas trataremos de resumir la regulación de las Sociedades de Auditoría en el marco establecido por la Ley de Sociedades Profesionales, a través de la doctrina emitida por la Dirección General de los Registros y del Notariado sobre el particular.

El primer problema que plantea el «status quaestionis», es determinar si una sociedad que tiene por objeto el ejercicio de la actividad profesional de auditoría, debe someterse imperativamente al régimen impuesto por la Ley de Sociedades Profesionales.

La cuestión no es baladí, ya que el sometimiento de una sociedad a la regulación establecida en la Ley de Sociedades Profesionales implica, entre otras obligaciones, el cumplimiento de lo recogido en la Disposición Transitoria Primera en cuanto a la adaptación de los estatutos e inscripción en el Registro Mercantil, teniendo su incumplimiento importantes consecuencias, como a continuación comprobaremos.

La propia Ley de Sociedades Profesionales es la que determina su ámbito de aplicación. Así, en el artículo primero, establece que las sociedades profesionales se regirán por lo dispuesto en la Ley de So- 
ciedades Profesionales y, supletoriamente, por las normas correspondientes a la forma social adoptada.

La Ley entiende por sociedad profesional aquella que tenga por objeto social el ejercicio en común de una actividad profesional.

A los efectos de esta Ley, se entiende que es actividad profesional aquélla para cuyo desempeño se requiere titulación universitaria oficial o titulación profesional para cuyo ejercicio sea necesario acreditar una titulación universitaria oficial e inscripción en el correspondiente Colegio Profesional.

Hay que entender, a los efectos previstos en la Ley de Sociedades Profesionales, que existe ejercicio en común de una actividad profesional cuando los actos propios de la misma sean ejecutados directamente bajo la razón o denominación social y le sean atribuidos a la sociedad los derechos y obligaciones inherentes al ejercicio de la actividad profesional como titular de la relación jurídica establecida con el cliente.

Por último, permite que las sociedades profesionales puedan adoptar cualquiera de las formas jurídicas admitidas en nuestro ordenamiento, ya sean capitalistas (anónima o de responsabilidad limitada) o personalistas (colectiva o comanditaria), siempre y cuando se constituyan con los requisitos establecidos en su articulado.

Ha tenido que ser la Dirección General de los Registros y del Notariado, a través de su doctrina ${ }^{1}$, la que arrojara luz al problema del sometimiento o no, de una sociedad que tiene por objeto el ejercicio de la actividad profesional de auditoría, a la Ley de Sociedades Profesionales.

La Resolución de 5 de marzo de 2009 de la Dirección General de los Registros y del Notariado, publicada con fecha 25 de marzo de 2009 en el BOE n. ${ }^{\circ}$ 72, es la que sirve de guía para el estudio y resolución de la polémica.

Esta Resolución estudia la inscripción de una escritura de modificación de estatutos sociales y nombramiento de administrador de una sociedad de responsabilidad limitada que tenía por objeto, entre otras actividades, la auditoría de cuentas y que, según se expresaba en dicha escritura, figuraba inscrita en el Registro Oficial de Auditores de Cuentas del Instituto de Contabilidad y Auditoría de Cuentas.

1 Vid. RRDGRN de 5 de Marzo de 2009, 6 de Marzo de 2009, 1 de Abril de 2009, 1 de Abril de 2009, 1 de Abril de 2009, 2 de Abril de 2009, 28 de Mayo de 2009 y 28 de Mayo de 2009. 
El Registrador Mercantil suspendió la inscripción solicitada porque, a su juicio, al no constar que la sociedad se había adaptado a las previsiones de la Ley de Sociedades Profesionales, y habiendo transcurrido el plazo de un año desde la entrada en vigor de dicha Ley, había quedado cerrada la hoja registral.

El recurrente, por su parte sostenía que la auditoría de cuentas no era una actividad profesional a los efectos de lo establecido en la Ley de Sociedades Profesionales; y que la sociedad tenía también por objeto otras actividades para las que no se exige acreditación de un título ni inscripción colegial, por lo que se trataba de una sociedad mixta cuya única obligación era la de estar inscrita en el Registro Oficial de Auditores de Cuentas.

El Centro Directivo comienza su fundamentación jurídica, realizando una exposición acerca de cuál es el ámbito de aplicación de Ley de Sociedades Profesionales, llegando a la conclusión de que existen determinadas normas que, cualquiera que sea el tipo societario al que se acoja la sociedad profesional, son imperativas, mientras que otras, en cambio, son de carácter dispositivo, sin prejuzgar sobre cuáles tengan una u otra naturaleza.

Prosigue su argumentación determinando también cuál es el ámbito de aplicación y régimen de la Ley 19/1988, de 12 de julio, de Auditoría de Cuentas, que incorporó la VIII Directiva comunitaria (84/253/CEE) y estableció el nuevo régimen legal de la actividad auditora, admitiendo que fuera realizada por sociedades.

A la vista de dicho régimen, el Centro Directivo afirma que la sociedad de auditoría de cuentas constituye un ejemplo de sociedad ejerciente de una actividad propia de determinados profesionales que reúnan los requisitos exigidos por su legislación especial, admitida en nuestro ordenamiento con anterioridad a la entrada en vigor de la Ley de Sociedades Profesionales, toda vez que se permitía que fuera la propia sociedad, como titular de la relación jurídica establecida con el cliente, la que realizara la actividad de auditoría.

La Disposición Adicional Primera de la Ley de Sociedades Profesionales, establece que sus preceptos serán de aplicación, en lo no previsto en su normativa especial, a quienes realicen la actividad de auditoría de cuentas de forma societaria, y que únicamente a los efectos de lo dispuesto en la Ley de Sociedades Profesionales, se considerará como registro profesional de las sociedades de auditoría y de colegiación de los socios de éstas el Registro Oficial de Auditores de Cuentas. 
La Dirección General de los Registros y del Notariado señala que, del sentido propio de las palabras empleadas en esta norma legal, se desprende inequívocamente que, respecto del ejercicio societario de la actividad auditora, la Ley de Sociedades Profesionales tiene carácter de derecho supletorio en relación con la legislación de auditoría de cuentas.

Lo que se pretende con dicha disposición es, por un lado, dejar clara la subsistencia de la normativa especial vigente sobre la actividad de auditoría de cuentas ejercida por sociedades, así como la que se pueda promulgar en el futuro, por lo que respecto de aquellos extremos en los que haya una regulación diferente, prevalecerá siempre la de la Ley de Auditoría de Cuentas.

Pero, por otro lado, al ordenar la aplicación supletoria de la Ley de Sociedades Profesionales, implica que en todos aquellos aspectos que no son objeto de específica regulación por la Ley de Auditoría de Cuentas habrá de aplicarse la Ley de Sociedades Profesionales, en cuanto no resulte incompatible con aquella regulación especial.

Como consecuencia de la aplicación preferente de la normativa especial sobre auditoría de cuentas, se considera que la sociedad misma es la auditora, la ejerciente de la actividad profesional, aunque falte el requisito de titulación universitaria en sus miembros. Se considera, por excepción, que la falta de dicho título queda compensada con creces por determinada formación práctica profesional de los mismos, de suerte que está plenamente justificada la aplicación del régimen que se deriva de la normativa especial de auditoría de cuentas.

De la comparación de las regulaciones legales de auditoría de cuentas con la específica de sociedades profesionales, resulta que el legislador acota la actividad que puede constituir el objeto de las sociedades profesionales al exigir en el artículo 1.1 de la Ley de Sociedades Profesionales, los requisitos de titulación determinada e inscripción en un Colegio Profesional, pero también establece coherentemente que a determinada actividad como es la auditoría de cuentas, que requiere especiales garantías y es también reglada, le sea aplicable dicha Ley de Sociedades Profesionales en los aspectos de la regulación de las sociedades auditoras que no estén contemplados en la Ley de Auditoría de Cuentas y sean compatibles con el régimen específico disciplinado en ésta.

Por ello, el Centro Directivo llega a dos conclusiones respecto a lo recogido en la Disposición Adicional Primera de la Ley de Sociedades Profesionales: 
Las Sociedades Profesionales de Auditoría EN La DOCTRina...

1. Las sociedades auditoras pueden ser sociedades profesionales constituidas formalmente conforme a dicha Ley, si nacen con cumplimiento de los requisitos establecidos en la misma, o si se adaptan voluntariamente a sus previsiones, en cuanto sean compatibles con las exigencias y la regulación específica de la Ley de Auditoría de Cuentas, es decir, con especialidades como la posibilidad de falta de titulación universitaria así como la sustitución de la colegiación e inscripción en Registro profesional por la inscripción en el Registro Oficial de Auditores de Cuentas.

2. Aun cuando las sociedades auditoras no revistan el ropaje societario de sociedades profesionales acomodadas a la Ley de Sociedades Profesionales, los preceptos de ésta les serán aplicables supletoriamente.

\section{EXPRESION DEL OBJETO SOCIAL EN LOS ESTATUTOS DE UNA SOCIEDAD PROFESIONAL DE AUDITORÍA.}

Como ya hemos señalado, las sociedades auditoras tienen la posibilidad de constituirse como sociedades profesionales si nacen con cumplimiento de los requisitos establecidos en la Ley de Sociedades Profesionales, o si se adaptan voluntariamente a sus previsiones, en cuanto sean compatibles con las exigencias y la regulación específica de la Ley de Auditoría de Cuentas.

La Dirección General de los Registros y del Notariado ha fijado cuales son los requisitos que deben cumplirse en la constitución o adaptación de una sociedad profesional de auditoria o de cualquier otra clase, en cuanto a la expresión del objeto social en sus estatutos.

La doctrina viene recogida en la Resolución de la Dirección General de los Registros y del Notariado de 1 de marzo de 2008, publicada con fecha 17 de marzo de 2008, en el BOE n. 66.

La resolución resuelve la negativa de la Registradora Mercantil a inscribir una escritura de modificación de estatutos de una sociedad limitada, otorgada con el fin de adaptarla a lo previsto en la Ley de Sociedades Profesionales.

La Sra. Registradora deniega la inscripción del documento en base a cinco motivos. Los motivos $3^{\circ}$ y $5^{\circ}$ no fueron impugnados por el notario autorizante. Y en cuanto aquí nos interesa debemos centrarnos en el análisis del primero de los motivos. 
La Sra. Registradora para denegar la inscripción de la escritura presentada, expresa algunas objeciones a distintos apartados del artículo estatutario relativo al objeto social, separando dentro de dicho objeto, los que pertenecen estrictamente al ámbito de las actividades propias y características de los socios profesionales, de otras actividades, que en su criterio, o bien no las puede asumir una sociedad externa, pues son específicas de cada persona jurídica (la elaboración de las cuentas anuales y el informe de gestión), o son manifestaciones de la capacidad de obrar de la sociedad (lo que no puede constar, en el artículo estatutario relativo al objeto social. por prohibirlo el Reglamento del Registro Mercantil en su artículo 178.2) o son propias de otros ámbitos profesionales (como los regulados por la Ley de Auditoria de Cuentas de 12 de julio de 1.988) o, en último término, pueden ser llevados a cabo por otros muchos profesionales distintos a los integrantes de la sociedad en cuestión.

Es decir, lo que la Sra. Registradora señala es que el objeto social debe expresar con claridad y concisión la actividad profesional de que se trate, para lo que considera que bastaría configurar el objeto social expresando simplemente la clase de profesional a que se refiere, una formulación genérica y precisa al mismo tiempo que permite incluir en la actividad profesional todo lo que de sí pueda dar la profesión de que se trate.

El Centro Directivo señala que la propia disposición estatutaria no especifica la concreta profesión cuyo ejercicio constituye el objeto social de la sociedad. Continua diciendo que, si a ello se añade la exigencia legal y reglamentaria de claridad y precisión en la determinación del objeto social, debe concluirse que una enumeración de actividades como la que es cuestionada no puede ser admitida.

Sobre esta materia el Centro Directivo continúa sentando doctrina al establecer que, al margen de que una adecuada interpretación de la disposición relativa a algunas de las actividades especificadas conforme a los artículos 1281, 1284 y 1285 del Código Civil, pudiera salvar alguna de las objeciones que alega la Registradora, la intención evidente de los otorgantes reflejada en el negocio documentado, la valoración global de sus cláusulas y su inteligencia en el sentido más adecuado para que produzcan efecto llevaría a la conclusión de que las actividades incluidas bajo las letras $« \mathrm{a} »^{2} \mathrm{y} « \mathrm{~b} »^{3}$ del artículo esta-

\footnotetext{
2 "El asesoramiento en materia contable, la confección de libros de contabilidad y demás libros obligatorios y la elaboración de las cuentas anuales y de los informes de gestión».

${ }^{3}$ «La planificación y dirección de la organización contable, de la contabilidad y de la administración».
} 
tutario que cuestiona la Registradora no pueden sino referirse a otras sociedades distintas de la que ahora se constituye, lo cierto es que esa enumeración, relación, descripción o reseña de actividades y competencias que constituye objeto de debate no sólo es insuficiente para, per se, caracterizar debidamente a la sociedad, sino que puede inducir a error acerca de la naturaleza de su objeto social en perjuicio de la propia sociedad, de los terceros y del tráfico en general.

Y eso es así porque, o bien estas actividades serán en muchos supuestos compartidas con otros profesionales o auxiliares del comercio, lo que podrá dar lugar a cuestiones de competencia o compatibilidad, o es tan difícil que lleguen a enumerarse de modo completo que pudiera pensarse que la persona jurídica no es un verdadero profesional por no contemplar en su artículo estatutario relativo al objeto social una actividad que en realidad sí es específica de la profesión.

Así, la Dirección General de los Registros y del Notariado, reitera su doctrina al respecto ${ }^{4}$ señalado que la determinación de las actividades que integren el objeto social por el género incluye todas sus especies, de modo que la enumeración de éstas últimas tan sólo tiene sentido cuando tenga por objeto excluirlas y no a la inversa, ante la práctica imposibilidad de hacerlo de forma exhaustiva y el consiguiente riesgo de que esa enumeración se entienda en el sentido de que tan sólo las incluidas en ella quedan integradas en el objeto y no las restantes.

Asimismo, puede también suceder que por este procedimiento enunciativo lo que la Sociedad consiga sea incluir en sus estatutos un objeto prolijo y posiblemente genérico a fuerza de querer detallar y pormenorizar lo que con absoluta claridad se puede resumir con las palabras que la Ley utiliza: «el objeto social es el ejercicio en común de una profesión determinada».

Para el Centro Directivo, y según la doctrina expuesta, resulta evidente que, designada la profesión, sobra la descripción. Si un profesional, según la normativa vigente, puede ejercer todas esas actividades y está investido de una concretas competencias, es indiferente que sea persona física o persona jurídica, y en este último caso, constituida como sociedad profesional, inscrita como tal en el Registro Mercantil y en el del Colegio correspondiente, nada cambiará el hecho de que en su objeto social estatutario no aparezcan pormenori-

${ }^{4}$ Vid. RRDGRN de 11 de octubre y 15 de noviembre de 1993, 22 de mayo y 7 de noviembre de 1997 y 18 de noviembre de 1999. 
zadas y descritas todas y cada una de ellas; mientras que la seguridad jurídica en general se beneficiará de esa exposición precisa e incuestionable del objeto social.

\section{APLICACIÓN DE LA DISPOSICION TRANSITORIA PRIMERA DE LA LEY DE SOCIEDADES PROFESIONALES A LAS SOCIEDADES PROFESIONALES DE AUDITORIA.}

En la Disposición Transitoria Primera de la Ley de Sociedades Profesionales relativa al plazo de inscripción de las sociedades profesionales en el Registro Mercantil, se recogen una serie de plazos sobre los que hay que prestar atención, ya que los mismos son de plena aplicación, y, por tanto, obligado cumplimiento en todo el territorio nacional, dado el carácter de esta Ley tal y como se determina en su Disposición Final Primera.

En el párrafo primero de la citada Disposición Transitoria Primera, se dice que las sociedades constituidas con anterioridad a la entrada en vigor de la Ley y a las que les fuera aplicable a tenor de lo dispuesto en su artículo 1.1, deberán adaptarse a las previsiones de la presente Ley y solicitar su inscripción, o la de la adaptación en su caso, en el Registro Mercantil, en el plazo de un año desde la entrada en vigor de ésta.

Así pues, partiendo de la fecha de entrada en vigor de la Ley de Sociedades Profesionales ${ }^{5}$, el día 16 de junio del 2008 venció el plazo reseñado, dentro del cual las sociedades que tengan por objeto social el ejercicio en común de una actividad profesional y hubieran sido constituidas antes de la entrada en vigor de la Ley, deberán haber adaptado sus Estatutos a la previsto en la Ley de Sociedades Profesionales, y haber solicitado su inscripción en el Registro Mercantil.

En el párrafo segundo y tercero de la Disposición Transitoria Primera se establecen las consecuencias jurídicas que conlleva el incumplimiento de la obligación de adaptación e inscripción en los plazos señalados en el párrafo primero del precepto, a saber, el cierre registral y la disolución de pleno derecho.

El estudio de la aplicación de las sanciones que impone la Disposición Transitoria Primera lo circunscribiremos a las sociedades profesionales de auditoria, y realizaremos el análisis a través de la doctrina de la Dirección General de los Registros y del Notariado,

${ }^{5}$ La Ley de Sociedades Profesionales entró en vigor el 16 de junio del 2007, 
destacando dos Resoluciones: la Resolución de 5 de marzo de 2009 de la Dirección General de los Registros y del Notariado, publicada con fecha 25 de marzo de 2009 en el BOE n. ${ }^{\circ} 72$ y la Resolución de 6 de marzo de 2009 de la Dirección General de los Registros y del Notariado, publicada con fecha 25 de marzo de 2009 en el BOE n. ${ }^{\circ} 72$ :

A) La importante y clarificadora Resolución de 5 de marzo de 2009 del Centro Directivo, a la que ya hemos hecho mención, señala que la Disposición Transitoria Primera de la Ley de Sociedades Profesionales debe ser entendida según el sentido literal de la misma, toda vez que alude exclusivamente a las sociedades a las que sea aplicable in toto dicha Ley, a tenor de lo establecido en su artículo 1.1 , por estar constituidas para ejercer como tales sociedades aquellas profesiones para cuyo desempeño se requiere titulación universitaria oficial, o titulación profesional para cuyo ejercicio sea necesario acreditar una titulación universitaria oficial, e inscripción en el correspondiente Colegio Profesional.

Además, no puede ignorarse que la última razón de ser de la misma Ley de Sociedades Profesionales como norma de garantía es la seguridad jurídica de las sociedades profesionales, a las que facilita un régimen peculiar hasta ahora inexistente y establecimiento de un sistema de garantías para los clientes o usuarios, que ven ampliada la esfera de sujetos responsables mientras que las sociedades auditoras ya cuentan con un régimen específico que en lo esencial es considerado suficientemente garantista.

Asimismo, han de prevalecer en dicha labor hermenéutica las exigencias derivadas de los principios de seguridad jurídica y de conservación de la empresa, que imponen una interpretación restrictiva de la referida norma sancionatoria.

De este modo, las sociedades auditoras no adaptadas a la Ley de Sociedades Profesionales podrán seguir ejerciendo la actividad de auditoría de suerte que, con independencia de las consecuencias que haya de tener la aplicación supletoria de dicha Ley, y sin mengua de las facultades que en el ámbito de sus competencias correspondan al Instituto de Contabilidad y Auditoría de Cuentas, no pueden entrar en juego las sanciones establecidas por la mencionada Disposición Transitoria Primera.

Por todo lo expuesto, la Dirección General acuerda estimar el recurso interpuesto y revocar la calificación del Registrador, ya que al tratarse de una sociedad de auditoría de cuentas a la que han de ser de aplicación meramente supletoria los preceptos de la Ley de So- 
ciedades Profesionales pero sin obligación de adaptarse a sus previsiones, debe concluirse que no entra en juego la norma del apartado número 2 de la Disposición Transitoria Primera de dicha Ley y, por ende, el consiguiente cierre registral para el título cuya calificación ha sido impugnada.

B) La Resolución de 6 de marzo de 2009 de la Dirección General de los Registros y del Notariado resuelve un supuesto en el que se pretende la inscripción de una escritura de elevación a público de acuerdos sociales de cambio de estructura del órgano de administración, nombramiento de administrador único y modificación de estatutos de una sociedad de responsabilidad limitada que tiene por objeto la auditoría de cuentas y que, mediante dicha modificación estatutaria pretende ampliar el objeto social a otras actividades.

El Registrador Mercantil suspende la inscripción solicitada porque, a su juicio, al tratarse de una sociedad profesional sujeta a la Ley de Sociedades profesionales y no haber presentado en el Registro la escritura de adaptación a la misma antes del transcurso del plazo de dieciocho meses desde la entrada en vigor de dicha Ley, ha quedado disuelta de pleno derecho, según las Disposiciones Adicional Primera y Transitoria Primera de la misma.

La sociedad recurrente sostiene que la auditoría de cuentas no es una actividad profesional a los efectos de lo establecido en la Ley de Sociedades Profesionales; y que, por ello, esta Ley no es de aplicación a la actividad de auditoría sino únicamente a través de su disposición adicional primera, con carácter supletorio, en todo lo no previsto en su normativa especial, por lo que no obliga a las sociedades de auditoría a adaptarse a sus previsiones ni son aplicables las medidas establecidas en la disposición transitoria citada por el Registrador.

El Centro Directivo utiliza los mismos razonamientos jurídicos que empleó en su Resolución de 5 de marzo del 2009 y que ya hemos expuesto, para estimar el recurso interpuesto y revocar la calificación del Registrador, ya que al tratarse de una sociedad de auditoría de cuentas a la que han de ser de aplicación meramente supletoria los preceptos de la Ley de Sociedades Profesionales pero sin obligación de adaptarse a sus previsiones, debe concluirse que no entra en juego la norma del apartado número 3 de la Disposición Transitoria Primera de dicha Ley y, por ende, entiende que la sociedad no ha quedado disuelta de pleno derecho. 


\section{LAS SOCIEDADES PROFESIONALES DE AUDITORIA MULTIDISCIPLINARES}

El artículo 3 de la Ley de Sociedades Profesionales, regula el tipo social profesional multidisciplinar, autorizando que las sociedades profesionales puedan ejercer varias actividades profesionales, siempre que su desempeño no se haya declarado incompatible por norma de rango legal o reglamentario.

Como ya señalamos, la Ley de Sociedades Profesionales ha sido modificada por la Ley 25/2009, de 22 de diciembre, conocida como Ley Omnibus, de modificación de diversas leyes para su adaptación a la Ley 17/2009, de 23 de noviembre, sobre el libre acceso a las actividades de servicios y su ejercicio,

Una de esas modificaciones afectan al citado artículo 3. Así, la nueva redacción establece respecto a las sociedades multidisciplinares que, las sociedades profesionales podrán ejercer varias actividades profesionales, siempre que su desempeño no se haya declarado incompatible por norma de rango legal.

El artículo admite el ejercicio de varias actividades profesionales, pero, en atención a la posible colisión con principios deontológicos y corporativos, señalaba en su redacción original que «siempre que su desempeño no se haya declarado incompatible por una norma de rango legal o reglamentario».

Pues bien, tras la indicada modificación, se ordena que la incompatibilidad sólo puede ser declarada por «una norma de rango legal».

Esto es una consecuencia de los principios fundamentales en los que se inspiró la Ley 17/2009, de 23 de noviembre, sobre el libre acceso a las actividades de servicios y su ejercicio, ya que dicha Ley permite limitar la actividad multidisciplinar siempre y cuando se cumplan una serie de requisitos, a saber, que la limitación venga establecida por ley, que la prohibición se imponga para salvaguardar la independencia y la imparcialidad de las profesiones implicadas y de esta manera evitar en lo posible conflicto de intereses, y por último que la medida sea proporcionada a los fines que se pretenden conseguir.

Esta reforma se complementa con la modificación de la Ley de Colegios Profesionales, en la que se establece que, en todo caso, los requisitos que obliguen a ejercer de forma exclusiva una profesión o que limiten el ejercicio conjunto de dos o más profesiones, serán sólo los que se establezcan por Ley. Añadiendo que, en ningún caso, 
los Colegios Profesionales ni sus organizaciones sociales podrán, por sí mismos o a través de sus estatutos o el resto de la normativa colegial, establecer restricciones al ejercicio profesional en forma societaria.

Son los supuestos de sociedades multidisciplinares de abogados y auditores las que mayor polémica suscitan.

La jurisprudencia del Tribunal de Justicia de la Unión Europea ${ }^{6}$ justifica las restricciones para el ejercicio conjunto de ambas actividades porque puede existir una cierta incompatibilidad entre la actividad de asesoramiento que ejerce el abogado y la actividad de control desarrollada por el auditor.

Tras el establecimiento de esta nueva jurisprudencia europea, el Estatuto de la Abogacía estableció restricciones para el ejercicio conjunto de ambas profesiones.

Pues bien, esas restricciones, a partir de la reforma introducida por la Ley Omnibus y la Ley 17/2009 no son válidas, ya que solo una norma con rango de Ley podrá decretar o bien la incompatibilidad absoluta para el ejercicio multidisciplinar o bien la incompatibilidad relativa.

En la actualidad, el debate está abierto como consecuencia de la tramitación del proyecto de ley de auditoría que tendrá que decidir sobre esta delicada cuestión.

El 23 de abril del 2010 se público en el Boletín Oficial de las Cortes Generales la remisión del Proyecto de Ley ${ }^{7}$ aprobado por la Comisión de Economía y Hacienda del Congreso de los Diputados, a la Comisión de Economía y Hacienda del Senado para la presentación de enmiendas.

En lo que aquí nos interesa, el Proyecto de Ley modifica el artículo 8 de la Ley 19/1988 de 12 de julio, de Auditoría de Cuentas, relativo al principio de independencia.

El citado artículo establece que los auditores de cuentas y las sociedades de auditoría deberán ser independientes, en el ejercicio de su función, de las entidades auditadas, debiendo abstenerse de actuar

${ }^{6}$ Cfr. Sentencia del Tribunal de Justicia de la Unión Europea de 19 de febrero del 2002, asunto Wouters (C-309/99).

7 Proyecto de Ley por el que se modifica la Ley 19/1988, de 12 de julio, de Auditoría de Cuentas, la Ley 24/1988, de 28 de julio, del Mercado de Valores y el texto refundido de la Ley de Sociedades Anónimas aprobado por el Real Decreto Legislativo 1564/1989, de 22 de diciembre, para su adaptación a la normativa comunitaria. 
cuando su independencia en relación con la revisión y verificación de los estados financieros $\mathrm{u}$ otros documentos contables pudiera verse comprometida, fijando que las amenazas a la independencia podrán proceder de factores como la autorrevisión, interés propio, abogacía, familiaridad o confianza, o intimidación.

En el apartado tercero del artículo se establece una lista de circunstancias, además de los supuestos de incompatibilidad previstos en otras leyes, en las que en todo caso, se considerará que el auditor de cuentas o la sociedad de auditoría firmante del informe de auditoría, no goza de la suficiente independencia en el ejercicio de sus funciones respecto de una empresa o entidad. Entre esas circunstancias en la letra g) se recoge la prestación de servicios de abogacía para la entidad auditada.

Por lo tanto, el artículo 8 de la Ley 19/1988 de 12 de julio, de Auditoría de Cuentas tras la modificación que podría sufrir, contendría el régimen del deber de independencia que han de observar los auditores de cuentas en el ejercicio de su actividad, el cual se garantizaría, por una parte, en la enunciación de un principio general de independencia que obliga a todo auditor a abstenerse de actuar cuando pudiera verse comprometida su objetividad en relación a la información económica financiera a auditar, y, por otra parte, en la enumeración de un conjunto de circunstancias, situaciones o relaciones específicas en las que se considera que, en el caso de concurrir, los auditores no gozan de independencia respecto a una entidad determinada, siendo la única solución o salvaguarda posible la no realización del trabajo de auditoría.

Las últimas noticias aparecidas en los medios de comunicación acerca de las enmiendas al Proyecto de $\mathrm{Ley}^{8}$, asegura que los grupos parlamentarios del Partido Popular, Convergencia y Unión y Partido Nacionalista Vasco han alcanzado un acuerdo, en el Senado, para plantear un nuevo régimen de incompatibilidad entre las actividades de abogacía y auditoría. Por su parte, los populares atenúan su postura y ya no apuestan por una separación radical entre ambas profesiones.

El texto propuesto prohíbe que la sociedad de auditoría preste simultáneamente servicios de abogacía a la entidad auditada, salvo que dichos servicios los lleven a cabo personas jurídicas distintas y con consejos de administración diferentes, y sin que puedan referirse a la resolución de litigios sobre cuestiones que puedan tener una in-

8 Cfr. Expansión.com del 22 de abril del 2010. 
cidencia significativa, "medida en términos de importancia relativa», en los estados financieros correspondientes al periodo o ejercicio auditado.

En cualquier caso, los grupos no descartan nuevos acuerdos en la votación en Comisión, aunque la previsión es que la sesión se centre únicamente en ratificar el texto aprobado por la ponencia sin más modificaciones.

Habrá que esperar al texto definitivo de la Ley para poder hacer una valoración respecto al nuevo marco normativo relativo a la incompatibilidad entre las actividades de abogacía y auditoria en el ámbito de las sociedades profesionales multidisciplinares.

\section{CONCLUSIONES}

A tenor de la doctrina de la Dirección General de los Registros y del Notariado, las sociedades de auditoría pueden constituirse, de manera voluntaria, conforme a la exigencias de la Ley de Sociedades Profesionales e incluso pueden adaptarse a la misma. Cuando las sociedades de auditoría no adopten el tipo social de sociedades profesionales, la Ley de Sociedades Profesionales les será de aplicación supletoria.

De este modo, las sociedades de auditoría no adaptadas a la Ley de Sociedades Profesionales, podrán seguir ejerciendo su actividad sin que entren en juego las sanciones establecidas por la Disposición Transitoria Primera de la Ley de Sociedades Profesionales.

Por otra parte, a la hora de determinar las actividades que integran el objeto social de una sociedad profesional, y en particular de una sociedad profesional de auditoría, bastará que se haga por el género de dichas actividades, ya que se entenderá que incluye todas sus especies.

Respecto a las sociedades multidisciplinares de abogados y auditores, el Tribunal de Justicia de la Unión Europea establece restricciones para el ejercicio conjunto de ambas actividades, por incompatibilidad entre la actividad de asesoramiento que ejerce el abogado y la actividad de control desarrollada por el auditor.

El Proyecto de Ley (publicado en el Boletín Oficial de las Cortes Generales el 23 de abril del 2010), por el que se modifica la Ley de Auditoría de Cuentas, la Ley del Mercado de Valores y el Texto Refundido de la Ley de Sociedades Anónimas, tiene como objetivo fun- 
damental trasponer a nuestro ordenamiento jurídico, la doctrina del Tribunal de Justicia de la Unión Europea respecto a las sociedades multidisciplinares de abogados y auditores, mediante la modificación, entre otros, del artículo 8 de la Ley de Auditoría de Cuentas, relativo al principio de independencia. 
